\title{
Reaprovechamiento y remediación de pasivos ambientales mineros
}

Jorge GutiérRez Sisniegas

Abogado por la Pontifica Universidad Católica del Perú.

Socio de Deustua \& Halperin Abogados.

SUMARI0:

I. Introducción.

II. Los pasivos ambientales y su reaprovechamiento.

III. Conclusión. 


\section{INTRODUCCIÓN}

Contablemente, el término "pasivo" está referido al conjunto de deudas que tiene una empresa con terceros. Cuando hablamos de pasivos ambientales, obviamente, nos referimos a deudas asociadas a la existencia de un daño ambiental ocasionado por las actividades económicas desarrolladas por una empresa. Este tipo de deudas comprende distintos conceptos como el costo de las obligaciones de remediación o mitigación medioambiental, las multas administrativas aplicables conforme a ley o las indemnizaciones por la afectación de intereses particulares o colectivos.

Con frecuencia los pasivos ambientales son consecuencia de actividades económicas que se desarrollaron en el pasado sin los cuidados ambientales que la ley exige en la actualidad. Algunos de ellos son tan antiguos que no se conoce al generador ni tienen un responsable identificable. En el Perú, los pasivos ambientales de naturaleza minera se han convertido en uno de los problemas de contaminación más serios del país.

\section{LOS PASIVOS AMBIENTALES Y SU REAPROVECHAMIENTO}

La Ley 28271, define los pasivos ambientales mineros como "aquellas instalaciones, efluentes, emisiones, restos o depósitos de residuos producidos por operaciones mineras, en la actualidad abandonadas o inactivas y que constituyen un riesgo permanente y potencial para la salud de la población, el ecosistema circundante y la propiedad". De acuerdo a la indicada ley, en caso de no poderse identificar al responsable del pasivo, el Estado debe hacerse cargo del mismo, asumiendo la obligación de ejecutar el cierre, con todos los costos que ello involucra, a fin de frenar la contaminación.

Desde el año 2004, el Ministerio de Energía y Minas (MEM) desarrolla la tarea de inventariar los pasivos ambientales mineros existentes e identificar a los responsables de la obligación de remediación y cierre. En la actualidad, el inventario contiene 6,847 pasivos ambientales mineros, la mayoría de los cuales no tiene un responsable identificado.

Como una alternativa para contribuir a la solución del agobiante problema que los pasivos ambientales representan para el Estado, el Reglamento de la ley en mención (Decreto Supremo 059-2005-EM) regula la denominada "remediación voluntaria" de pasivos ambientales mineros, una de cuyas modalidades es el reaprovechamiento de sustancias minerales. De acuerdo al Reglamento, el reaprovechamiento "consiste en la extracción de minerales de pasivos ambientales tales como desmontes, relaves $u$ otros que pudieran contener valor económico, determinando la obligación de su remediación ambiental".

Como sabemos, para la extracción de minerales desde su fuente natural (la corteza terrestre) se debe contar con un título de concesión minera. Sin embargo, en virtud a las normas señaladas, para la extracción de minerales de pasivos ambientales, solamente es necesario obtener el permiso correspondiente de la autoridad minera.

El solicitante de un permiso de reaprovechamiento debe demostrar su derecho sobre el pasivo ambiental, por ejemplo, a través de la constancia de inscripción en los Registros Públicos de la compraventa del depósito de relaves y el terreno donde se encuentran depositados.

El solicitante debe, también, presentar un Estudio de Impacto Ambiental (EIA), incluyendo un Plan de Cierre a nivel de factibilidad. EI EIA debe describir las medidas de mitigación aplicables para que desde un primer momento, se eliminen los impactos ambientales negativos. De igual modo, el Plan de Cierre debe detallar las actividades de cierre progresivo o concurrente, de cierre final y post-cierre del pasivo, e incluir las garantías financieras que aseguren su cumplimiento.

Es importante indicar que, el titular del derecho de reaprovechamiento no adquiere la responsabilidad por las infracciones ambientales en que hubiera incurrido el generador del pasivo 
ambiental. Tampoco, adquiere el derecho de reclamar al generador el reembolso de los gastos de remediación. Sin embargo, el generador se mantiene solidariamente responsable ante el Estado por el pasivo hasta su cierre definitivo.

A diferencia del concesionario, el titular del derecho de reaprovechamiento no está obligado al pago del Derecho de Vigencia. Tampoco, está sujeto al pago de la penalidad por falta de producción, ya que no se le exige cumplir con una producción mínima anual de minerales. Estas diferencias, se comprenden mejor si tenemos presente que el objetivo que se persigue con la entrega del permiso de reaprovechamiento no es promover la producción minera, sino más bien lograr la remediación del pasivo ambiental, cuyo costo, de otro modo, tendría que solventar el propio Estado.

Si bien, el reaprovechamiento de pasivos ambientales mineros es un mecanismo favorable para la recuperación ambiental, aún se desconoce cuál es su verdadero potencial en el Perú. Evidentemente, su ámbito de aplicación es limitado, ya que la extracción minera sólo podrá llevarse a cabo en algunos de ellos: aquellos que contengan minerales cuya recuperación sea económicamente viable.

Conforme al Fondo Nacional del Ambiente (FONAM) ${ }^{1}$, los pasivos ambientales mineros comprenden: bocaminas, chimeneas, cortes, depósitos de desmontes, depósitos de relaves o relaveras, media barretas, rajos, socavones, tajos, edificaciones e instalaciones. Evidentemente, por su naturaleza, no todos estos pasivos contienen residuos minerales $y$, en consecuencia, sólo una parte de ellos podrán ser materia de reaprovechamiento. Probablemente, los lugares más aparentes para el reaprovechamiento serán los depósitos de desmontes, las relaveras y los socavones, tajos y rajos.

Los depósitos de desmontes, también conocidos como "botaderos", y las relaveras contienen residuos minerales derivados de las actividades de extracción y de procesamiento, respectivamente. Los socavones, tajos y rajos están, más bien, vinculados a las áreas mineralizadas.

De acuerdo a las definiciones del FONAM, un depósito de desmonte es el área ocupada por los materiales extraídos de una mina que no contienen elementos valiosos o cuya obtención no es rentable para el generador, y que son dispuestos en un lugar donde no se realizan actividades de explotación. Un depósito de relaves, se define como el área ocupada por materiales sin valor, obtenidos como sub-producto del proceso de flotación. Estos materiales son, generalmente, dispuestos en una presa de sostenimiento ubicada en una ladera, una quebrada o en una pampa.

Un socavón, es el espacio vacío que queda después de la explotación de una mina subterránea, y se ubica, inmediatamente, después de la bocamina. Los socavones pueden ser muy superficiales o muy profundos, dependiendo del volumen del mineral que se ha extraído. El concepto de "tajo" corresponde, más bien, al espacio vacío dejado por la explotación de minerales a cielo abierto, mientras que un "rajo" es el área de explotación de afloramientos de minerales de veta, por lo general, de dimensiones mucho menores.

\section{CONCLUSIÓN}

El potencial del reaprovechamiento como mecanismo de remediación ambiental podría estimarse sobre la base de la información con la que cuenta el Ministerio de Energía y Minas, respecto de cada uno de los pasivos que tiene inventariados, estableciendo cuántos de ellos corresponden a botaderos, relaveras, socavones, tajos y rajos. Un paso adicional sería promocionar el sistema de reaprovechamiento facilitando a los potenciales interesados la información sobre cuáles son las áreas que contienen este tipo de pasivos.

1. Ver Portal del FONAM: http://www.fonamperu.org/general/pasivos/bienvenida.php. 